DE DE GRUYTER OPEN
Journal of Intercultural Management

Vol. 6, No. 4, December 2014, pp. 289-305

DOI 10.2478/joim-2014-0051

Birgit Burböck*

FH-JOANNEUM University of Applied Sciences, Graz, Austria

Sandra Schnepf*

FH-JOANNEUM University of Applied Sciences, Graz, Austria

Stephan Pessl*

FH-JOANNEUM University of Applied Sciences, Graz, Austria

\title{
Personality Differences in Organisational Socialisation Tactics
}

\begin{abstract}
The demographic shifts, the increased workforce mobility, and the shortage of skilled workers have led to a new thinking within human resource management. To address this issue, organisations adapt their methods towards a higher focus on their employees. The purpose of this paper is therefore the identification of organisational socialisation tactics, which are classified into the individualized socialisation strategy and the institutionalised socialisation strategy. Studies show that the institutionalised socialisation strategy causes better results in terms of newcomer adjustment than the individualized socialisation strategy. In this context, the instiutionalised socialization strategy determines that organisations consider newcomers' personalities and demographic characteristics. The results of this paper support this argument and reveal that students in the DACH region differ in their organisational socialisation preferences. In other words, a well-structured organisational socialisation process, which considers newcomers' personalities can lead to a competitive advantage for organisations.
\end{abstract}

Key Words: Organisational Socialisation, Socialisation Tactics, Institutionalised Socialisation, Socialisation Preferences

\section{Introduction}

For new employees the first days and weeks of their employment are often related to high levels of stress and anxiety (Van Maanen, 1978) as they are entering

* birgit.burboeck@fh-joanneum.at; Sandra.schnepf@fh-joanneum.at;

Stephan.pess1@edu.fh-joanneum.at 
an unfamiliar environment (Louis, 1980). Literature often refers to this initial time as organisational socialisation. Organisational socialisation is characterised by the newcomers' learning about the organisation, their work group, and the necessary skills and knowledge for their work tasks (Fisher, 1986).

This initial period of time is very crucial, both for the organisation and new employees, as newcomers are very receptive for new information during the organisational socialisation (Berthel and Becker, 2013). Moreover, newcomers realize during their starting time if they fit to the organisation. This fact strongly influences their decision to stay within the company in the long run (Kammeyer-Mueller and Wanberg, 2003). According to Allen (2006), many new employees decide against their company, which leads to a high fluctuation especially in the first year of employment. A high fluctuation in the first year results in a negative outcome for organisations as the expenses for the recruiting and selection process will be higher than the actual value which the new employee contributed to the organisation (Bauer et al., 1998).

Organisations have to be aware of the fact that the way how they treat their new employees has wide-ranging consequences. In fact, organisations have the possibility to influence the newcomers' learning processes by the use of different organisational socialisation tactics (Van Maanen, 1978). Various organisational socialisation tactics not only have an influence on the organisational socialisation process itself, but also on the newcomers' adjustment to the organisation (Gruman et al., 2006; Jones, 1986; Saks et al., 2007). Organisations can improve these organisational socialisation processes by the choice of appropriate organisational socialisation tactics and also by considering new employees' personality (Gruman and Saks, 2011). If organisations make investments in organisational socialisation practices that focus on newcomers' personality traits, there might be valuable changes in new employees' work quality and retention in the longer term (Cable et al., 2013). Bauer et al. (1998, p. 164) stated that "newcomers' preferences for different types of socialisation tactics is an issue that deserves future research attention". On the basis of this statement and the important personality traits of new employees, Gruman and Saks (2011) conducted a study which shows socialisation preferences of Canadian students according to their personality traits. However, it is not advisable to generalise the outcomes to other newcomers (Gruman and Saks, 2011), as cultural diversity might have an influence on socialisation preferences (Bauer et al., 1998). As there is no actual data about the DACH region in terms of students' socialisation preferences, our study analyses the organisational socialisation preferences of students in the DACH region and reveals preference differences according to their various personality traits and additionally their demographic characteristics. 


\section{Organisational Socialisation Tactics}

New employees are in a so-called anxiety-producing situation when they start in a new company. Newcomers are motivated to reduce the grade of anxiety and want to learn their new tasks quickly and carefully. In this context, organisational socialisation tactics are a crucial part for organisations and the whole socialisation process (Van Maanen, 1978). In figure 1, Jones (1986) classifies the organisational socialisation tactics into the context, content, and social area, and differentiates between the institutionalised and the individualised strategy, which are considered as organisational socialisation strategies. The difference between the two strategies is that, for the new employee, the individualised socialisation strategy leads to a more innovative role interpretation, while the institutionalised socialisation strategy leads to a more custodial role interpretation (Ashforth et al., 2007; Jones, 1986; Saks et al. 2007).

Figure 1: A Classification of Socialisation Tactics (adapted based on Jones, 1986, p.

263)

\begin{tabular}{|l|l|l|}
\cline { 2 - 3 } \multicolumn{1}{c|}{} & Institutionalised & Individualised \\
\hline Context Area & $\begin{array}{l}\text { Institutionalised } \\
\text { Context Tactics }\end{array}$ & $\begin{array}{l}\text { Individualised } \\
\text { Context Tactics }\end{array}$ \\
\hline Content Area & $\begin{array}{l}\text { Institutionalised } \\
\text { Content Tactics }\end{array}$ & $\begin{array}{l}\text { Individualised } \\
\text { Content Tactics }\end{array}$ \\
\hline Social Area & $\begin{array}{l}\text { Institutionalised } \\
\text { Social Tactics }\end{array}$ & $\begin{array}{l}\text { Individualied } \\
\text { Social Tactics }\end{array}$ \\
\hline
\end{tabular}

Source: own research

According to Jones (1986), the context area of the socialisation describes the way in which organisations provide the necessary information to new employees. The second area is about the actual content which the given information to newcomers has and provides newcomers with specific information concerning their future organisational process like the timeframe of organisational socialisation. The third and last area is called social area and is focuses on social and interpersonal relationships between the new employee and responsible persons for the organisational socialisation process. Tasks related to the social area include dealing with feedback, the identity recognition of the new employee and the new employee's support by a trusted organisational insider (Bauer et al., 2007).

The institutionalised socialisation strategy provides new employees with information in a structured way and thereby reduces their grade of anxiety (Saks et al., 
2007). By the use of the institutionalised socialisation strategy, the values and norms of the organisation can be passed to the new employee much more sophisticated lay (Cable et al., 2013). The institutionalised socialisation strategy has a positive influence on custodial role orientation, job satisfaction, organisational commitment, and the proactive socialisation behaviour of new employees. Furthermore, the institutionalised socialisation strategy has a negative influence to the newcomers' role ambiguity, role conflict, and intentions to quit (Ashforth and Saks, 1996; Ashforth et al., 2007; Changhong Lu and Tjosvold, 2013; Gruman et al., 2006; Jones, 1986; Saks et al., 2007).

By using the individualised socialisation strategy, the organisational socialisation process is characterised by a certain absence of structure (Saks et al., 2007) and an approach towards sink-or-swim (Berthel and Becker, 2013). In a company, which applies the individualised socialisation strategy, new employees often start to work immediately at their workplace. Employees are expected to figure out the necessary skills and working procedures, as well as information about the organisation, on their own, without much help of a structured socialisation programme. As the environment is defined by a very informal approach, new employees have to have a more proactive behaviour to understand the company's expectations and circumstances (Bauer and Erdogan, 2010). However, the individualised socialisation strategy provides the new employee with the possibility to develop his or her own point of view, which can lead to an innovative interpretation of his or her role within the organisation (Jones, 1986).

\section{Personality in the Organisational Socialisation}

In the socialisation process, not only the choice of a socialisation tactic or strategy is important, but also the personality of new employees has to be considered. In fact, newcomer adjustment can be improved by socialisation practices which focus on the newcomers' personal identities (Cable et al., 2013). During the socialisation process, newcomers not only seek to reduce their uncertainty and anxiety (Van Maanen, 1978), but also desire for certain grades of authenticity and self-expression. Socialisation tactics which pay attention to new employees' personality traits are more likely to be effective in terms of employment relationship between newcomers and organisations (Cable et al., 2013). Paying attention to the importance of personality for organisational socialisation, the socialisation should be adapted to the newcomers' personality traits to a certain extent (Cable et al., 2013). This raises the question of which personality traits do have an actual influence on the preferences for the different organisational socialisation tactics. Some studies discussed this question (Bauer et al., 1998; Feldman, 1990; Gruman and Saks, 2011), and, by using the approach of Gruman and Saks (2011), the following empirical study examines the influence of six defined personality traits to preferences for the different socialisation tactics. 


\section{Hypotheses}

As stated by Gruman and Saks (2011), newcomers' personality traits have an influence on socialisation preferences. Additionally, Bauer et al. (1998) outlined that newcomers' demographic characteristics might have an influence on their preferences for socialisation tactics. Based on these two statements, Figure 2 shows the expected influence according to six personality traits for newcomers' socialisation preferences, by the use of the illustrated hypotheses.

Figure 2: Influence of Personality on Socialisation Preferences

\begin{tabular}{|c|c|c|c|}
\hline Personality/Tactics & Institutionalised Context & Institutionalised Content & Institutionalised Social \\
\hline Extraversion & H1a & H1b & H1c \\
\hline Agreeableness & $\mathrm{H} 2 \mathrm{a}$ & $\mathrm{H} 2 \mathrm{~b}$ & $\mathrm{H} 2 \mathrm{c}$ \\
\hline Conscientiousness & H3a & $\mathrm{H} 3 \mathrm{~b}$ & $\mathrm{H} 3 \mathrm{c}$ \\
\hline Neuroticism & $\mathrm{H} 4 \mathrm{a}$ & $\mathrm{H} 4 \mathrm{~b}$ & $\mathrm{H} 4 \mathrm{c}$ \\
\hline Openness & H5a & $\mathrm{H} 5 \mathrm{~b}$ & $\mathrm{H} 5 \mathrm{c}$ \\
\hline Proactive Personality & H6a & $\mathrm{H} 6 \mathrm{~b}$ & H6c \\
\hline
\end{tabular}

The first hypothesis is about the influence of students' extraversion on their preference for the institutionalised socialisation tactics. In this context, extraverted persons are described as persons who are sociable, gregarious, assertive, talkative, and active (Barrick and Mount, 1991). Therefore, we assume that students high on extraversion prefer the institutionalised socialisation tactics as they like being around other people and socialize with them (Gruman and Saks, 2011).

H 1: The grade of students' extraversion has a positive influence on their preference for the institutionalised a) context, b) content, and c) social socialisation tactics.

The second hypothesis is about the influence of students' agreeableness to their preference for the institutionalised socialisation tactics. Persons who have a high degree of agreeableness are courteous, flexible, trusting, good-natured, cooperative, forgiving, soft-hearted, and tolerant (Barrick and Mount, 1991). Furthermore, agreeable individuals try to avoid controversies and are more likely to interact with other persons (Wanberg and Kammeyer-Mueller, 2000). Additionally to these facts, agreeable persons accept existing procedures in the organisation to a higher extent, whereby it is more likely that students high on agreeableness prefer the institutionalised socialisation tactics (Gruman and Saks, 2011).

Hypothesis 2: The grade of students' agreeableness has a positive influence on their preference for the institutionalised a) context, b) content, and c) social socialisation tactics. 
The third hypothesis describes influence of students' conscientiousness to their preference for the institutionalised socialisation tactics. A conscientious person is more likely to be careful, thorough, responsible, organised, hardworking, achievement-orientated, and persevering (Barrick and Mount, 1991). Based on the mentioned attributes, students high on conscientiousness probably prefer a socialisation that facilitates organisation and careful planning, which characterises the institutionalised socialisation tactics (Gruman and Saks, 2011).

Hypothesis 3: The grade of students' conscientiousness bas a positive influence on their preference for the institutionalised a) context, b) content, and c) social socialisation tactics.

The fourth hypothesis illustrates the influence of students' neuroticism to their preference for the institutionalised socialisation tactics. Some attributes which describe a neurotic personality are anxiousness, depression, angriness, embarrassment, emotionality, and insecureness (Barrick and Mount, 1991). As neurotic persons tend to interpret new situations often very negatively (Wanberg and Kammeyer-Mueller, 2000), they are more likely to prefer socialisation which gives them structure and social support (Gruman and Saks, 2011). Therefore, we assume that students high on neuroticism prefer the institutionalised socialisation tactics (Gruman and Saks, 2011).

Hypothesis 4: The grade of students' neuroticism has a positive infuence on their preference for the institutionalised a) context, b) content, and c) social socialisation tactics.

The fifth hypothesis deals with the influence of students' openness to their preference for the individualised socialisation tactics. Persons with a high grade of openness are characterised as imaginative, cultured, curious, original, broad-minded, and intelligent (Barrick and Mount, 1991). Considering the mentioned attributes, open individuals' act more actively regarding the information and feedback seeking (Wanberg and Kammeyer-Mueller, 2000). In contrast to neurotic individuals, open individuals are more curious and tolerant about new situations, whereby it is more likely that students high on openness prefer the individualised socialisation tactics as these tactics are less structured and offer a higher chance for creativity and innovation (Gruman and Saks, 2011).

Hypothesis 5: The grade of students' openness has a positive influence on their preference for the individualised a) context, b) content, and c) social socialisation tactics.

The sixth hypothesis describes the influence of the proactive personality of students on their preference for the individualised socialisation tactics. People with a proactive personality have a desire to influence their environment by their own actions (Kammeyer-Mueller et al., 2011). Therefore, it is more likely that students with a high grade of proactive personality prefer the individualised socialisation tactics, as these tactics give them a better opportunity to follow an innovative approach and change the status-quo (Gruman and Saks, 2011).

Hypothesis 6: The grade of students' proactive personality has a positive influence on their preference for the individualised a) context, b) content, and c) social socialisation tactics. 


\section{Methods}

The target group for this study is defined with current students who have their present main residence in Germany, Austria, or Switzerland. These three countries are defined in this paper as DACH region. During the survey period, 322 participants started the online-questionnaire. 60 participants did not finish the whole questionnaire, which implies a dropout rate of 18.63 percent. 262 fully completed and therefore valid questionnaires were received in total.

Subtracting eight questionnaires from non-student participants, in total 254 questionnaires were used for the data analysis process. The average age of the participants was 23.88 years with a range from 19 to 47 years and forty one percent indicated their gender as male. The average working experience was 29.88 months with a range from zero to 350 months. Regarding the current residence of the students, 67 percent stated Austria, 23 percent Germany, and 10 percent Switzerland.

To collect the necessary data, a questionnaire-link was distributed via available e-mail addresses of students and personal messages to other students via social media platforms. The link was valid and online from May $1^{\text {st }}, 2014$ until May 14 ${ }^{\text {th }}, 2014$, which implies a survey period of exactly two weeks. As Malhotra (2012) stated, the distribution via e-mail and social media is a well-working way to generate a large number of responses. This data collection method also has the advantage that it keeps the costs on a very low level as there are for instance, no printing costs for the surveys. As the data collection via e-mail and social media allows the researcher to customize the addressed persons (Malhotra, 2012), a random sampling was applied.

In empirical research the increasing availability of large data sets has enabled great advances. To draw a sufficiently large sample size a snowball sampling approach was applied. By the use of the snowball principle, the researcher can be supported by the help of other persons and institutions, which are distributing the questionnaire among their network. This way of collecting data is especially beneficial, if, in a random sampling, not all persons of a target group are specifically reachable, but reachable through the connection to other persons of the target group (Häder, 2010). However, the drawback of snowball sampling is due to several sources of bias. (Atkinson and Flint, 2001) Since the recruiting of new respondents is influenced by the respondents themselves, the researcher has only limited control of the final participants in the sample. Additionally, if strong homophily exists between individuals, the researcher is confronted with a homogenous cluster. (Illenberger\& Flötteröd, 2012). As this situation is given for the target group of students in the DACH region, the snowball principle was applied in the data collection procedure.

After the completion of the data collection period, the following statistics can be stated:

- 3,426 students were contacted via e-mail and 123 students were contacted via 
personal messages on social media platforms, which implies a total of 3,549 directly contacted students

- 322 participants could be generated during the survey period, which results in a response rate of 9.07 percent

By reviewing the statistics, it has to be mentioned that the snowball principle used is not included. As the 123 students who were contacted via social media platforms were asked to distribute and share the questionnaire-link to students in their own network, the actual response rate is probably lower than the presented 9.07 percent.

\section{Five-Factor Model of Personality}

For the first section in which data about students' personality characteristics were collected, five personality factors were used. The five-factor model with the factors extraversion, agreeableness, conscientiousness, neuroticism, and openness is very robust and provides an adequate framework for defining and testing of hypotheses in terms of individual differences in personality (Barrick and Mount, 1991). As scales which are short in length reduce some forms of bias caused by participants' overtiredness and carelessness (Podsakoff et al., 2003), the 10-item short version of the five-factor model by Rammstedt and John (2007) was used. Although there are some slight reliability and validity losses in comparison to the original 44item version of the five-factor model (John et al., 1991), it is argued that for research where time is limited the 10 -item short version is an adequate assessment of personality (Rammstedt and John, 2007). For the five-factor model, the participants provided responses on a 5-point Likert scale ranging from 1 ("strongly disagree") to 5 ("strongly agree"). The higher the scores on each scale, the higher was the participant's personality characteristic for the queried personality trait. The negatively polarized items were recoded before the analysis tests started. The coefficient alphas for the five factors were: extraversion $(\alpha=0.815)$, agreeableness $(\alpha=0.687)$, conscientiousness $(\alpha=0.739)$, neuroticism ( $\alpha=0.756$ ), and openness $(\alpha=0.743)$.

To collect data about the proactive personality of the participants, a modified 10-item scale by Seibert et al. (1999) was used. In comparison to the original 17-item scale by Bateman and Crant (1993), the losses in terms of reliability and validity are minimal, whereby the shortened version "appears to be comparable to the full 17-item version" (Seibert et al., 1999, p. 419). As already mentioned, a short questionnaire length prevents some bias (Podsakoff et al., 2003), which supports the use of the modified 10-item scale. For the modified 10-item proactive personality scale, the participants provided responses on a 7-point Likert scale ranging from 1 ("strongly disagree") to 7 ("strongly agree"). The higher the scores on each scale, the higher was the participant's grade of proactive personality. For the proactive personality factor the coefficient alpha was $(\alpha=0.812)$. 
The third section of the questionnaire asked participants about demographical characteristics. This section includes questions about participant's current student status and current main residence, which are both criteria for exclusion, if participants stated no or if they stated other countries than Germany, Austria, or Switzerland.

The students' preferences for the organisational socialisation were ascertained by using the 30-item measure developed by Jones (1986). As our study is about the students' preferences for the different tactics, the original items were slightly changed to give students the possibility to express their preferences. In this context, students were asked to imagine a situation where they start to work in a new organisation and could decide how they would like to run through the first 90 days of employment. The participants provided responses on a 7-point Likert scale ranging from 1 ("strongly disagree") to 7 ("strongly agree"). The higher the scores on each scale, the higher was the participant's preference for the institutionalised socialisation tactics. To ensure that this statement is also valid for the negatively polarized items, these negative items were recoded before the execution of the analytic tests. The adjusted coefficient alpha for the three scales was: context $(\alpha=0.732)$, content $(\alpha=0.748)$, and social $(\alpha=0.618)$.

\section{Results}

Table 1 shows the means and standard deviations of the three socialisation preference scales. In the first place, it is important to mention that the results of all three areas indicate a general preference for the institutionalised socialisation as they were all above the midpoint. Secondly, it can be seen that for the institutionalised context tactics the preference is higher than the preference for the institutionalised content and social tactics.

Table 1: Means of Socialisation Areas

\begin{tabular}{|r|c|c|c|}
\hline \multicolumn{4}{|c|}{ Descriptive Statistics for the Socialisation Preferences } \\
\hline & Context Tactics & Content Tactics & Social Tactics \\
\hline Mean & 5.122 & 4.865 & 4.995 \\
\hline Standard Deviation & 1.435 & 1.515 & 1.414 \\
\hline
\end{tabular}

Source: own research

To test the six hypotheses of our study, three multiple linear regressions were conducted. For each of these regressions, one area of socialisation tactics was regressed on the six personality variables. Table 2 summarizes the outcomes of these analyses. 
Table 2: Multiple Linear Regressions for Personality Variables and Socialisation Tactics Preferences

\begin{tabular}{|c|c|c|c|}
\hline \multicolumn{4}{|c|}{ Multiple Linear Regressions } \\
\hline & Context Tactics & Content Tactics & Social Tactics \\
\hline Extraversion & $-0.144^{*}$ & -0.091 & 0.010 \\
\hline Agreeableness & 0.123 & -0.020 & 0.028 \\
\hline Conscientiousness & $0.147^{*}$ & $0.190^{* *}$ & 0.108 \\
\hline Neuroticism & 0.062 & $0.132^{*}$ & $0.147^{*}$ \\
\hline Openness & 0.047 & 0.048 & -0.009 \\
\hline Proactive Personality & 0.072 & $0.201^{* *}$ & 0.124 \\
\hline $\mathbf{R}^{2}$ & $0.051^{*}$ & $0.090^{* *}$ & 0.041 \\
\hline Adjusted $\mathbf{R}^{2}$ & $0.028^{*}$ & $0.068^{* *}$ & 0.018 \\
\hline
\end{tabular}

Source: own research

As indicated in Table 2, the personality variables show a significant amount of variance in the context of socialisation tactics $\left(R^{2}=0.051, p<0.05\right)$ and the content of socialisation tactics $\left(R^{2}=0.090, p<0.01\right)$, but no significance in the social socialisation tactics $\left(R^{2}=0.041, p>0.05\right)$. Among the six personality variables, extraversion was negatively and significantly related to the institutionalised context socialisation tactics $(\beta=-0.144, \mathrm{p}<0.05)$. Conscientiousness was positively and significantly related to both the institutionalised context $(\beta=0.147, \mathrm{p}<0.05)$ and institutionalised content $(\beta=0.190, \mathrm{p}<0.01)$ socialisation tactics. These results support hypotheses $3 \mathrm{a}$ and $3 \mathrm{~b}$. Neuroticism was positively and significantly related to both the institutionalised content $(\beta=0.132, \mathrm{p}<0.05)$ and institutionalised social $(\beta=0.147, \mathrm{p}<0.05)$ socialisation tactics. These results support hypotheses $4 \mathrm{~b}$ and $4 \mathrm{c}$. The proactivity personality of students was positively and significantly related to the institutionalised content socialisation tactics $(\beta=0.201, \mathrm{p}<0.01)$. For the personality variables agreeableness and openness, no significant relation to at least one of the three socialisation tactics could be identified.

\section{Discussion}

Similar to the results of Gruman and Saks (2011), our findings confirm that personality traits have an influence on the socialisation preferences. Gruman and Saks (2011) detected that especially the students' agreeableness significantly influences the students' preferences for all three areas of institutionalised socialisation tactics. Moreover, they stated that the students' personality traits influence above all the students' preferences for the institutionalised social socialisation tactics. In fact, the students' grade of agreeableness did not significantly influence the students' preferences for any of the three areas of socialisation in this study. The results indicated rather that the students' grades of conscientiousness and neuroticism are 
the most important personality traits in predicting the students' preferences for the institutionalised socialisation tactics. Also the second main statement by Gruman and Saks (2011) could not be approved as our study indicated that the students' personality traits influence above all the students' preferences for the institutionalised content socialisation tactics. However, Gruman and Saks (2011) stated that the students' personality traits significantly influence students' preferences for the institutionalised content tactics, which confirms our results.

Apart from the two mentioned comparisons, the investigations in terms of proactive personality revealed a quite unexpected result. Although it was assumed that students with a high grade of proactive personality prefer the individualised socialisation tactics than students with a lower grade of proactive personality, the results show the exact opposite, especially for the content socialisation area. These results are partly the same as the results by Gruman and Saks (2011), with the difference, that in our study, a much higher significance can be seen. A possible reason for this result might be that newcomers need a structured socialisation process before they are able to act out their proactive personality by seeking feedback and building relationships (Griffin et al., 2000). To sum up the study results, three main findings can be stated. Firstly, and apart from the hypotheses, the study showed that students have a general preference for the institutionalised socialisation tactics. Secondly, in terms of personality, especially the students' grades of conscientiousness and neuroticism have the most significant influences for students' socialisation preferences. Thirdly, the students' personality influences above all students' preferences the institutionalised content socialisation tactics.

\section{Limitations}

The target group for our study is strictly limited to current students from the $\mathrm{DACH}$ region. Associated to this target group, it is generally not advisable to generalise the results to other types of potential new employees who have for instance no university education (Gruman and Saks, 2011). In terms of the study design, some further limitations have to be made. By the use of a cross-sectional design through different topics in the survey and self-reported data, a common-method bias might influence the results. The risk of such a common-method bias can be reduced through methods like the use of existing scales with multiple items, different scale anchors and values, and negatively worded items, which were applied in the questionnaire of our study. The use of self-report data is, to a certain extent, influenced by the respondent's mood and condition and therefore a risk in terms of common-method bias (Podsakoff et al., 2003).

\section{Conclusion}

Our study evaluated the topic organisational socialisation and focused in the first place on the different socialisation tactics and the classification of these tactics. 
The empirical part dealt with the socialisation preferences and potential differences regarding newcomers' personality and demographic characteristics. By using the available academic literature and the results of the conducted empirical study, the following can be concluded:

Organisational socialisation is an important topic for organisations as the first days and weeks of a new employee are a crucial time for the further collaboration. In fact, organisations have the opportunity to influence the outcomes of the organisational socialisation by the use of different socialisation tactics and strategies. The tactics can be classified both in areas and strategies. The identifiable areas are the context area, which describes the way how organisations are providing the organisational socialisation process to new employees, the content area, which is about time regulations and the framework for organisational socialisation, and the social area, which contains the interpersonal factor in the organisational socialisation of newcomers.

In terms of strategies, two general strategies are identified in our study, namely the institutionalised and the individualised socialisation strategy. The main difference between institutionalised and the individualised socialisations strategy is that the institutionalised socialisation is characterised by a more formal approach, which leads to a more custodial role orientation for newcomers. In contrast to that, the individualised socialisation strategy is characterised by a more informal and flexible approach, which leads to a more innovative role orientation for newcomers. Beyond that the institutionalised socialisation strategy generates positive outcomes for new employees' organisational commitment, job satisfaction, and proactive socialisation behaviour and negatively influences new employees' role ambiguity, role conflict, and intentions to quit. Our findings reveal that students from the DACH region have a general preference for the institutionalised socialisation strategy. Considering the identified positive outcomes of the institutionalised socialisation tactics, this general preference is not very surprising as the institutionalised socialisation strategy provides structure, guidance, and information that can decrease the students' uncertainty and anxiety in the initial time of their employment.

Through the investigation of the six stated hypotheses, it was revealed that the students' personality characteristics do matter for their socialisation preferences. In terms of personality, the students' grades of conscientiousness and neuroticism have the biggest influence on their socialisation preferences towards institutionalised socialisation tactics, while the students' grades of extraversion and proactive personality have only slighter influences. For the personality traits agreeableness and openness our study showed that both are actually not significantly related to students' socialisation preferences. It can be concluded that students in the DACH region have a general preference for the institutionalised socialisation strategy. The degree, however, varies across students' personality traits and demographic characteristics. 


\section{Implications for Practice}

Since the initial period of time are crucial for the individual and the organisation the results of this research have implications for new employees and organisations before and after starting with the new job. Organisations might discuss the socialisation process with new employees prior to entry to better understand the expectations and preferences of their new employees. If organisations try to match the socialization preferences with their actual socialisation experience they may avoid high fluctuation in the first year. (Bauer et al. 1998)

That being said, it seems that individuals prefer the institutionalised context tactics. This seems especially true for students who are beginning a full-time job after their graduation. These graduates will benefit from the context and structure provided by the organisation. Moreover, to the extent that conscientiousness has a higher influence on the context tactics, compared to the other dimension, a proactive personality has the highest influence on content tactics while neuroticism influences most the social tactics. These finding suggest that individuals who are low on openness and extraversion are most at risk for poor adjustment and socialization within an organisation. Therefore, organisations are best advised to consider the needs of the newcomers when providing them with socialisation experiences. New employees with lower intentions of being open or extraverted will be most likely in need of and most likely to benefit from the socialisation tactics of the organisation. Organisations may facilitate the on-boarding process when providing newcomers with information and instruction on the expected proactive behaviour or implementing a social events with organisational members and by assigning newcomers a mentor for a given period of time.

Our findings that some students do not intend to be as proactive as others should give concern to universities and to organisations. Universities should develop their curriculas based on competences in which proactive behaviour is encouraged. Additional education of the students about the importance of proactive behaviour when beginning a new job may help students and organisations to reduce the fluctuation at the early entry stage.

\section{Implications for Research}

The findings of this study lead to several new areas of research. First, given that a different cultural background may have an influence on the socialization preference, in how far can we say, that a person from a given cultural background prefers one socialization tactic over the other? Second, assuming that individuals prefer a particular socialization tactics, what happens if these preferences are not met? Although Bauer et al. (1998) suggest that newcomers' job attitude might be affected by the extent to which the tactics used by their organisation are similar to their preferences, has not been researched yet. Future research might investi- 
gate on a comparison between institutionalised and individualised preferences. In other words, in how far do individuals prefer an organisation which provides new employees information in a structured way compared to an organisation with the absence of a structure with a sink-or swim approach? (Berthel and Becker, 2013)

What has been not addressed in this article is the estimation of moderating effects of demographic variables like age, gender or the grade of working experience. A person's age influences his or her values and attitudes to work, ability for physical and mental functioning, and thoughts about everyday topics and concerns (Jackson et al., 1993). Saks et al. (2007) argue that older students react differently to socialisation tactics as they have another kind of thinking than younger students (Saks et al., 2007). As older students are often more experienced than younger students and have a different self-evaluation, it is more likely that older students prefer the individualised socialisation tactics (Gruman and Saks, 2011). Also men's and women's reactions to socialisation tactics are indeed different (Lefkowitz, 1994). Men describe themselves as more mature, while important characteristics for women are their expressiveness and their concern for others (Lefkowitz, 1994). Generally men and women have a different social background (Alvesson and Biling, 1992), which leads to the assumption that there are gender differences in the preferences for the institutionalised socialisation tactics. Additionally, there might be a difference between inexperienced students and students with some work experience as inexperienced students have a greater need for information, structure, and guidance during the socialisation process (Saks, et al., 2007). Moreover, it is possible that more experienced students have different preferences as they have already gone through some kind of socialisation before. (Gruman and Saks, 2011)

From the methodological point of view a different sampling may reveal different results. Various methods to account for snowball sampling bias have been proposed in the past (Frank \& Snijders, 1994; Thompson \& Frank, 2000; Heckathorn, 2002; Chow and Thompson, 2003; Volz \& Heckathorn, 2008; Handcock \& Gille, 2010) Since snowball sampling can be implemented in quite different variants, each specification usually requires its own inference approach (Illenberger \& Flötteröd, 2012). Further research should therefore focus on the effects on variations in different sampling designs. And finally, because the participants of this study were students caution is required when generalizing the results. Studies using student samples are readily available, as these samples are convenient and readily accessible. Besides the accessibility, convenience and low cost, students are more open to complicated designs. This can yield data which otherwise would be hard to collect for from instance employees or managers. Bello et al. (2009) Studies from practise involving employees and managers would shed additional light on this research area. 


\section{Bibliography}

Allen, D. G. (2006). Do Organisational Socialisation Tactics Influence Newcomer Embeddedness and Turnover? Journal of Management (32 (2)), pp. 237-256.

Alvesson, M., \& Biling, Y. D. (1992). Gender and Organisation: Towards a Differentiated Understanding. Organisation Studies (13), pp. 73-102.

Ashforth, B. E., \& Saks, A. M. (1996). Socialisation Tactics: Longitudinal Effects on Newcomer Adjustment. Academy of Management Journal (39 (1)), pp. 149-178.

Ashforth, B. E., Sluss, D. M., \& Saks, A. M. (2007). Socialisation Tactics, Proactive Behavior, and Newcomer Learning: Integrating Socialisation Models. Journal of Vocational Behavior (70), pp. 447-462.

Atkinson, R. \& Flint, J. (2001) Accessing hidden and hard-to-reach populations: snowball research strategies. Social Research Update (33).

Barrick, M. R., \& Mount, M. K. (1991). The Big Five Personality Dimensions and Job Performance: A Meta-Analysis. Personnel Psychology (44), pp. 1-26.

Bateman, T. S., \& Crant, J. M. (1993). The Proactive Component of Organisational Behavior. Journal of Organisational Behavior (14), pp. 103-118.

Bauer, T. N., \& Erdogan, B. (2010). Organisational Socialisation: The Effective Onboarding of New Employees. In S. Zedeck, APA Handbook of Industrial and Organisational Psychology, Vol 3: Maintaining, Expanding, and Contracting the Organisation. APA Handbooks in Psychology. (pp. 51-64). Washington, DC: American Psychological Association.

Bauer, T. N., Bodner, T., Erdogan, B., Truxillo, D. M., \& Tucker, J. S. (2007). Newcomer Adjustment During Organisational Socialisation: A Meta-Analytic Review of Antecedents, Outcomes, and Methods. Journal of Applied Psychology (92 (3)), pp. 707-721.

Bauer, T. N., Morrison, E. W., \& Callister, R. R. (1998). Organisational Socialisation: A Review and Directions for Future Research. Research in Personnel and Human Resource Management (16), pp. 149-214.

Bello, D.; Leung, K.; Radebaugh, J. Tung, R. L. \& Van Witteloostujin (2009). From the editors: Student samples in international business research. Journal of International Business Studies. (40 (3)), pp. 361-364

Berthel, J., \& Becker, F. G. (2013). Personalmanagement (10 ed.). Stuttgart: Schaeffer-Poeschel.

Cable, D. M., \& Parsons, C. K. (2001). Socialisation Tactic and Person-Organisation Fit. Personnel Psychology (54), pp. 1-23.

Cable, D. M., Gino, F., \& Staats, B. R. (2013). Breaking Them in or Eliciting Their Best? Reframing Socialisation around Newcomer's Authentic Self-expression. Administrative Science Quarterly (58 (1)), pp. 1-36.

Changhong Lu, S., \& Tjosvold, D. (2013). Socialisation Tactics: Antecents for Goal Interdependence and Newcomer Adjustment and Retention. Journal of Vocational Behavior (83), pp. 245-254.

Chow, M. \& Thompson, S.K. (2003). Estimation with link-tracing sampling designs - a Bayesian approach. Survey Methodology (29 (2)), pp.197-205. 
Feldman, D. C. (1990). Summer Interns: Factors Contributing to Positive Development Experiences. Journal of Vocational Behavior (37), pp. 267-284.

Fisher, C. D. (1986). Organisational Socialisation: An Integrative View. Research in Personnel and Human Resource Management (4), pp. 101-145.

Frank, O. \& Snijders, T. (1994). Estimating the size of hidden population using snowball sampling; Journal of Official Statistics (10) (1), pp. 53-67

Griffin, A. E., Colella, A., \& Goparaju, S. (2000). Newcomer and Organisational Socialisation Tactics: An Interactionist Perspective. Human Resource Management Review (10 (4)), pp. 453-474.

Gruman, J. A., \& Saks, A. M. (2011). Socialisation Preferences and Intensions: Does One Size Fit All? Journal of Vocational Behavior (79), pp. 419-427.

Gruman, J. A., Saks, A. M., \& Zweig, D. I. (2006). Organisational Socialisation Tactics and Newcomer Proactive Behaviors: An Integrative Study. Journal of Vocational Behavior (69), pp. 90-104.

Häder, M. (2010). Empirische Sozialforschung: Eine Einführung (2 ed.). Wiesbaden: VS Verlag für Sozialwissenschaften und GWV Fachverlage GmbH.

Handcock, M.S. \& Gille, K.J. (2010). Modeling social networks from sampled data. Annals of Applied Statistics (4 (1)), pp. 5-25.

Heckathorn, D.D. (2002). Respondent-driven sampling II: deriving valid population estimates from chain-referral samples of hidden populations. Social Problems (49 (1)), pp. $11-34$.

Illenberger, J.; \& Flötteröd, G. (2012): Estimating network properties from snowball sampled data. Social Networks (34) pp. 701-711

Jackson, S. E., Stone, V. K., \& Alvaraz, E. B. (1993). Socialisation amidst Diversity: The Impact of Demographics on Work Team Oldtimers and Newcomers. Research in Organisational Behavior (15), pp. 45-109.

John, O. P., Donahue, E. M., \& Kentle, R. L. (1991). The Big Five Inventory - Versions 4a and 54. Berkeley, CA: University of California, Berkeley, Institute of Personality and Social Research.

Jones, G. R. (1986). Socialisation Tactics, Self-Efficacy, and Newcomers' Adjustments to Organisations. Academy of Management Journal (29 (2)), pp. 262-279.

Kammeyer-Mueller, J. D., \& Wanberg, C. R. (2003). Unwrapping the Organisational Entry Process: Disentangling Multiple Antecedents and Their Pathways to Adjustment. Journal of Applied Psychology (88 (5)), pp. 779-794.

Kammeyer-Mueller, J. D., Livingston, B. A., \& Liao, H. (2011). Perceived Similarity, Proactive Adjustment, and Organisational Socialisation. Journal of Vocational Behavior (78), pp. $225-236$

Lefkowitz, J. (1994). Sex-Related Differences in Job Attitudes and Dispositional Variables: Now You See Them. Academy of Management Journal (37 (2)), pp. 323-349. 
Louis, M. R. (1980). Surprise and Sense Making: What Newcomers Experience in Entering Unfamiliar Organisational Settings. Administrative Science Quarterly (25), pp. 226-251.

Malhotra, N. K. (2012). Basic Marketing Research (4 ed.). Upper Saddle River, NJ: Prentice Hall.

Phillips, J. M., \& Gully, S. M. (2013). Human Resource Management: International Edition. Mason, $\mathrm{OH}$ : Cengage South-Western.

Podsakoff, P. M., MacKenzie, S. B., Lee, J.-Y., \& Podsakoff, N. P. (2003). Common Method Biases in Behavioral Research: A Critical Review of the Literature and Recommended Remedies. Journal of Applied Psychology (88 (5)), pp. 879-903.

Rammstedt, B., \& John, O. P. (2007). Measuring Personality in One Minute or Less: A 10Item Short Version of the Big Five Inventory in English and German. Journal of Research in Personality (41), pp. 203-212.

Sackett, P. R., \& Larson, J. R. (1990). Research Strategies and Tactics in Industrial and Organisational Psychology. In M. D. Dunnette, \& L. M. Hough, Handbook of Industrial and Organisational Psychology, (2 ed., pp. 419-489). Palo Alto, CA: Consulting Psychologists Press.

Saks, A. M., Uggerslev, K. L., \& Fassina, N. E. (2007). Socialisation Tactics and Newcomer Adjustment: A Meta-Analytic Review and Test of a Model. Journal of Vocational Behavior (70), pp. 413-446.

Seibert, S. E., Crant, J. M., \& Kraimer, M. L. (1999). Research Reports: Proactive Personality and Career Success. Journal of Applied Psychology (84 (3)), pp. 416-427.

Thompson, S. K. \& Frank, O. (2000). Model-based estimation with link-tracing sampling design. Survey Methodology (26 (1), pp 87-98

Van Maanen, J. (1978). People Processing: Strategies of Organisational Socialisation. Organisational Dynamics (7 (1)), pp. 18-36.

Van Maanen, J., \& Schein, E. H. (1979). Towards a Theory of Organisational Socialisation. Research in Organisational Behavior (1), pp. 209-264.

Volz, E. \& Heckathorn, D.D. (2008). Probability based estimation theory for Respondent Driven Sampling. Journal of Official Statistics (24 (1)), pp. 79-97.

Wanberg, C. R., \& Kammeyer-Mueller, J. D. (2000). Predictors and Outcomes of Proactivity in the Socialisation Process. Journal of Applied Psychology (85 (3)), pp. 373-385.

Weidman, J. C. (2006). Socialisation of Students in Higher Education. In C. F. Conrad, \& R. C. Serlin, The SAGE Handbook for Research in Education: Engaging Ideas and Enriching Inquiry (pp. 253-262). Thousand Oaks, CA: Sage Publications. 